\title{
Two Cases of REM Sleep Behavior Disorder Combined with Severe Obstructive Sleep Apnea: Misdiagnosed as "Pseudo-REM Sleep Behavior Disorder” by Diagnostic Polysomnography
}

\author{
Hyun Jung Jang, Bomi Kim, Ho Sung Ryu, Gha-Hyun Lee, Sang-Ahm Lee \\ Department of Neurology, Asan Medical Center, University of Ulsan College of Medicine, Seoul, Korea
}

\author{
진단적 수면다원검사에서 가성-렘수면행동장애로 오진된, \\ 심한 폐쇄수면무호흡을 동반한 렘수면행동장애 2예 \\ 장현정, 김보미, 유호성, 이가현, 이상암 \\ 울산대학교 의과대학 서울아산병원 신경과학교실
}

Received September 16, 2013

Revised December 8, 2013

Accepted December 9, 2013

Address for correspondence

Sang-Ahm Lee, MD, PhD

Department of Neurology,

Asan Medical Center,

University of Ulsan

College of Medicine,

88 Olympic-ro 43-gil, Songpa-gu,

Seoul 138-736, Korea

Tel: $+82-2-3010-3445$

Fax: +82-2-474-4691

E-mail: salee@amc.seoul.kr
REM sleep behavior disorder (RBD) is a sleep disorder characterized by loss of normal voluntary muscle atonia during REM sleep associated with complex motor behavior while dreaming. Dream-enacting behaviors can also occur in patients with other sleep disorders such as obstructive sleep apnea (OSA). This clinical situation has been termed "pseudo-RBD”. In contrast, OSA causes frequent arousal, which may consequently result in masking of RBD symptoms. We reported two patients with severe OSA, who were initially diagnosed with "pseudo-RBD" but on continuous positive airway pressure (CPAP) titration, rediagnosed with "true-RBD". When RBD is clinically suspected but is not confirmed by diagnostic overnight polysomnography, we have to keep in mind that RBD could be detected during CPAP titration.

J Korean Sleep Res Soc 2013;10:62-65

Key Words: REM sleep behavior disorder, Pseudo-REM sleep behavior disorder, Obstructive sleep apnea, REM sleep without atonia.
렘수면행동장애(REM sleep behavior disorder, RBD)는 렘수면 동안 나타나는 근육이완의 소실로 인해, 꿈을 꾸면서 그 내용을 그대로 행동으로 옮기는 수면질환이다. ${ }^{1} 2005$ 년에 발표된 국제수면질환분류 기준 2판(the International Classification of Sleep Disorders, 2nd edition)에서는 렘수면행동 장애의 진단기준에 수면다원검사 소견이 필수적으로 포함되 었으며, 수면다원검사에서 렘수면 동안 근긴장도의 증가 (REM sleep without atonia)가 관찰되어야 하고, 병력에서 수면과 관련된 손상을 줄 수 있는 행동이 있거나 수면다원 검사에서 비정상적인 렘수면이상행동이 관찰된 경우에 진단 할 수 있다.

폐쇄수면무호흡증(obstructive sleep apnea, OSA)은 잠자 는 중에 일시적으로 상기도가 폐쇄되어 숨을 쉴 수 없는 상태 가 반복해서 나타나는 흔한 수면질환이다. 수면무호흡이 나
타나면 혈중산소포화농도가 떨어지고 교감신경계가 활성화 되며, 환자는 호흡을 위해 과도하게 호흡관련 근육을 수축하 게 되면서 각성(arousal)이 일어나게 된다. OSA가 심하면 각 성도 자주 발생하게 되고, 이러한 각성상태에서 렘수면행동 장애에서 보이는 유사한 이상행동을 보일 수 있다. Iranzo와 Santamaría는 문진상 렘수면행동장애가 의심되는 환자 16명 을 대상으로 수면다원검사를 시행하여 이를 증명하였다. ${ }^{2}$ 이 환자들은 병력상 수면시에 과격한 행동이 있었다. 모든 환자 는 쫓기거나 공격을 받는 것과 같은 불쾌한 꿈을 경험하였 으며 그 중 2 명은 배우자를 다치게 하였고, 5 명은 침대에서 떨어졌던 경험이 있었으며, 2 명은 본인이 신체적 손상을 입 었던 적이 있었다. 이 환자들의 수면다원검사 결과, 예상했던 렘수면행동장애는 관찰되지 않았고, 심한 폐쇄수면무호흡 증[apnea-hypopnea index(AHI)=67.5 \pm 18 .7]만 관찰되었다. 
지속기도양압(continuous positive airway pressure, CPAP) 치료를 시행 후 수면 중 렘수면행동장애가 관찰되지 않았다. 따라서 저자들은 이 환자들에게서 보였던 수면 중 이상행동 을 무호흡과 연관된 각성 때 보이는 렘수면행동장애-유사 행동, 즉 가성렘수면행동장애(pseudo-REM sleep behavior disorder)라고 명명하였다.

반대로, 심한 OSA 환자에서는 잦은 각성으로 인해 수면이 제대로 유지되지 못해 수면 분절(sleep fragmentation)이 많 이 나타나게 되며, 특히 렘수면에서는 근긴장도가 떨어지기 때문에 폐쇄성수면무호흡이 더 잘 발생하고, 이에 따라 각성 에 의한 렘수면의 수면분절은 비렘수면보다 더 자주 나타날 수 있다. 렘수면행동장애는 렘수면 때만 이상행동을 나타내 는데, 심한 OSA가 함께 있으면 렘수면이 유지되기가 힘들어 렘수면행동장애의 이상 행동이 미처 발현하지 못할 가능성 이 있다. 본 저자는 임상적으로 렘수면행동장애가 의심되나 수면다원검사에서 렘수면행동장애가 관찰되지 않고 폐쇄성
수면무호흡증이 관찰되어 가성렘수면행동장애로 추정하였 으나 지속기도양압적정검사(CPAP titration)를 하는 동안 렘수면행동장애가 발견된 2예를 경험하였다. 이를 통해 저 자들은 렘수면행동장애가 의심되는 환자에게서 수면다원검 사상 렘수면행동장애 없이 폐쇄성수면무호흡증만 발견된다 면 가성렘수면행동장애의 가능성도 있으나 수면무호흡으로 인한 수면분절로 렘수면행동장애의 근전도소견이 수면다원 검사에서 기록되지 않았을 수도 있다는 점을 본 증례를 통해 기술하고자 한다.

\section{증 례}

\section{증례 1}

72세 남자가 수면장애를 주소로 내원하였다. 환자는 3 4 년 전부터 수면 중에 소리를 지르며 팔다리를 휘두르는 증상 이 발생하였으며, 침대에서 떨어지기도 하였다. 렘수면행동

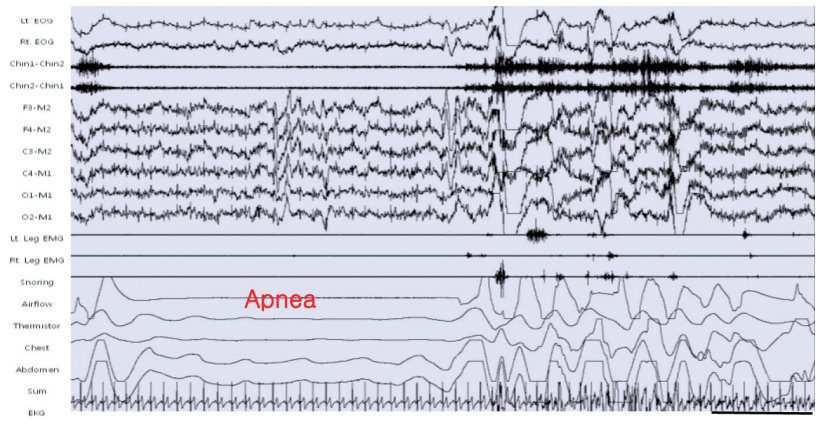

A

$15 \mathrm{sec}$

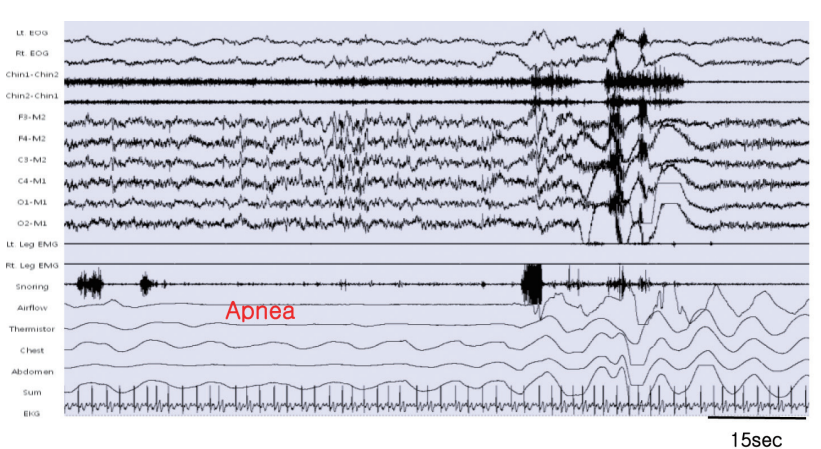

$B$

Figure 1. Increased muscle tone of chin and tibialis anterior muscle in first (A) and second (B) cases during arousal event on polysomnography, but no REM sleep behavior disorder was detected.

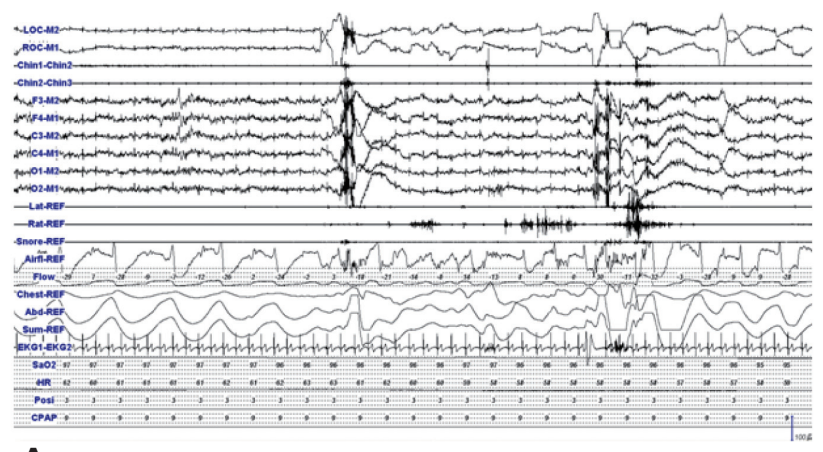

A

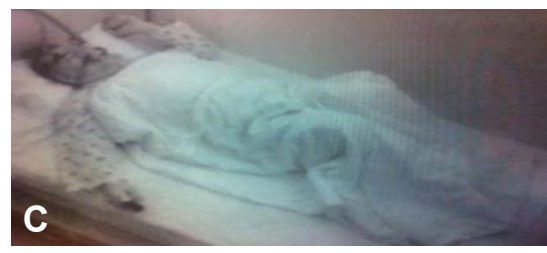

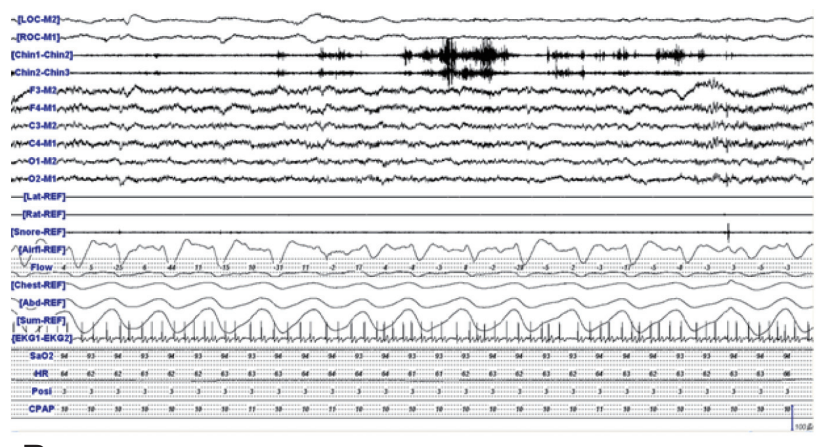

B
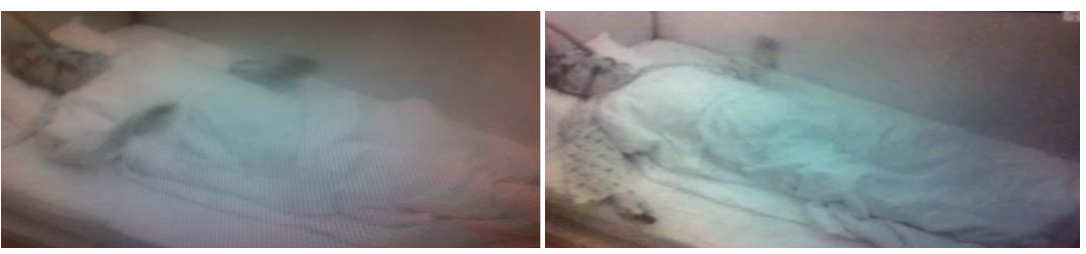

Figure 2. The $A$ and $B$ shows that the muscle tone of chin with or without both tibialis anterior muscle was increased during REM sleep in first (A) and second (B) cases, respectively. Simultaneously, excessive limb jerking acts of first case were caught on video monitoring (C). 
장애 선별질문(RBD screening questionnaire)에서는 11점으 로 렘수면행동장애를 시사하였다. 이외에도 환자는 밤에 긴 수면을 유지하지 못하고 자주 깨어나 아침에도 피곤한 증상 을 호소하였다. 동반하고 있는 내과 질환은 없었으며, 이학적 및 신경학적 이상소견도 보이지 않았다. 수면다원검사에서 수면구조는 수면1단계(N1 stage, 186분, 55.6\%)가 증가되었 으며, 수면3단계(N3 stage, 4분, 1.2\%)와 렘수면(REM sleep, 12 분, $3.6 \%)$ 은 감소되어 있었다. 무호흡-저호흡지수(AHI)는 $40 / \mathrm{h}$ 였으며, 총 각성지수(total arousal index)는 $43 / \mathrm{h}$, 무호 흡과 관련된 각성지수(apnea arousal index)는 비렘수면 때 28 $/ \mathrm{h}$, 렘수면 때 $50 / \mathrm{h}$ 였다. 검사 중 산소포화도의 저하는 $81 \%$ 까지 관찰되었다. 수면다원검사 중 무호흡과 연관하여 빈번 한 각성이 있었으나 렘수면 동안 근긴장도가 증가된 이상소 견은 없었으며 뇌파에서도 이상소견은 관찰되지 않았다(Fig. $1 \mathrm{~A})$. 따라서 수면무호흡증과 연관되어 나타난 가성렘수면행 동장애로 진단하였다. 지속기도양압 적정검사를 시행하였 으며, 검사상 $11 \mathrm{cmH}_{2} \mathrm{O}$ 가 적정수준으로 판단되었다. 렘수면 은 39분, $11.0 \%$ 로 이전보다 증가하였으며, 호흡장애지수(respiratory disturbance index)는 $51 / \mathrm{h}$ 에서 $10 / \mathrm{h}$ 로 개선되었 다. 렘수면 때 비정상적으로 근긴장도가 증가되는 소견이 관 찰되었으며, 비디오 모니터링에서도 렘수면 때 양팔의 움직 임이 지속적으로 관찰되어 렘수면행동장애가 있는 것으로 진단하였다(Fig. 2A, C).

\section{증례 2}

56세 남자가 수면 중 발생하는 팔다리의 이상행동으로 본 인이 다치거나 상대방에게 부상을 입히는 것을 주소로 내원 하였다. 증상은 20년 전부터 있었다고 하며 옆방에서 들릴 정 도로 소리를 지르거나 발이 벽에 부딪혀 발의 부상을 입은 적 도 있었다고 하였다. 빈도는 한 달에 두세 차례 정도로 빈번 하게 있었다. 렘수면행동장애 선별질문에서는 8점으로 렘수 면행동장애를 시사하였다. 코골이나 불면증 또는 낮 동안 졸 림 등의 다른 증상은 호소하지 않았다. 환자는 고혈압 이외 에는 다른 내과 질환은 동반하고 있지 않았으며 이학적 및 신경학적 검사도 정상이었다.

수면다원검사에서 수면구조는 비정상적으로 수면1단계 (N1 stage, 129분, 38.2\%)가 증가되었으며 렘수면단계(50분, $14.9 \%$ )는 감소되어 있었다. 무호흡/저호흡지수는 $37 / \mathrm{h}$, 총 각성지수는 $38 / \mathrm{h}$, 무호흡과 관련된 각성지수는 비렘수면 때 $30 / \mathrm{h}$, 렘수면 때 $46 / \mathrm{h}$ 였으며 산소포화도 저하는 $73.6 \%$ 까 지 관찰되었다. 턱에 부착된 근전도에서는 빈번한 각성과 연 관된 것을 제외하고는 렘수면행동장애를 시사할만한 근긴 장도의 이상은 없었다(Fig. 1B). 따라서 수면 중 발생했던 이
상운동에 대해서는 각성과 연관되어 나타난 것으로 보고, 중 증 폐쇄성수면무호흡증과 동반된 가성렘수면행동장애로 생 각하였다. 지속기도양압 적정검사에서 $9 \mathrm{cmH}_{2} \mathrm{O}$ 가 산소포화 도 $90 \%$, 호흡장애지수 $5 / \mathrm{h}$ 로 적정 수준으로 판단되었고, 이 검사에서는 렘수면단계가 65분(18\%)으로 증가되었다. 수면 때 각성은 의미 있게 감소하였고, 근긴장도가 비정상적으로 증가한 소견과 함께 총 4차례의 비정상행동이 관찰되었고, 그 중 2차례는 발차기나 주먹을 휘두르는 행동이 관찰되었 다(Fig. 2B). 그래서 이 환자는 지속기도양압 적정검사에서 렘수면행동장애로 진단되었다.

\section{고 찰}

렘수면행동장애가 있는 환자에서는 과격한 꿈과 연관하 여 소리를 지르거나 주먹을 휘두르는 등의 비정상적인 행동 을 보일 수 있다. 하지만 기타 다른 수면질환에서도 실제 렘 수면행동장애는 아니지만 수면 때 렘수면행동장애와 유사한 행동이 관찰될 수 있다. 수면무호흡증 환자에서는 무호흡과 연관하여 렘수면 또는 비렘수면단계에서 모두 수면의 분절이 자주 나타나며 이때 렘수면행동장애와 비슷한 움직임이 관 찰될 수 있다. 이를 임상적으로 가성렘수면행동장애로 정의 하였다. ${ }^{2}$ 난 논문에서 보면, 가성렘수면행동장애를 보인 수면 무호흡 환자들은 문진상 누군가에게 쫓기거나 공격 당하는 꿈을 꾸었고 비정상적인 발성(말하기, 소리지름, 울음)이나 과격한 행동(주먹 휘두르기, 발차기, 침대에서의 낙상)이 관 찰되었으며 실제 렘수면행동장애를 가진 환자와 임상양상이 매우 유사하였다. ${ }^{2}$ 가성렘수면행동장애의 병태생리는 아직 충분히 밝혀지지 않았다. 일부 저자들은 가성렘수면행동장애 가 심한 수면무호흡증 환자에서 나타나며 이 환자들에서 심 한 산소포화도 저하를 보고하였다. ${ }^{3}$ 이로 인해서 각성이 일 어나게 되고 혼돈된 상태에서 꿈과 연관하여 과격한 수면행동 장애가 나타나는 것으로 설명하고 있다. ${ }^{4}$

심한 무호흡증으로 인해 가성렘수면행동장애가 발생하는 경우도 있지만 앞서 소개한 증례와 같이 한 환자에게서 수면 무호흡증과 특발성 렘수면행동장애 두 질환이 함께 병발하 는 경우도 있을 수 있다. 우리 두 환자의 경우 병력 청취 및 렘 수면행동장애 선별질문에서 렘수면행동장애를 시사하였으 나 수면다원검사에서는 렘수면행동장애의 소견 없이 심한 폐 쇄수면무호흡만을 관찰할 수 있었다. 따라서 중증폐쇄수면무 호흡증 환자에서 수면무호흡과 연관된 각성 때 보일 수 있는 가성렘수면행동장애로 추정하였다. 수면무호흡증에 대한 치 료를 위해 추가적으로 지속기도양압 적정검사를 시행하였 고, 이 검사에서 렘수면행동장애가 진단되었다. 
Zhang 등은 렘수면행동장애 환자에게서 수면다원검사를 2 차례에 시행하여 수면다원검사의 민감도를 조사하였다. ${ }^{5}$ 그 결과, 렘수면 때 근긴장도의 증가가 첫째날 검사에서 $94.4 \%$, 둘째날 검사에서 $98.1 \%$ 에서 관찰되었다. 즉, 첫 수면다원검 사에서 약 6\%에서는 렘수면장애가 있지만 진단할 수 없었 다. 수면다원검사를 처음 시행할 때는 친숙하지 않은 환경에 서 수면을 취하게 되면서 수면의 유효성(sleep efficacy)이 떨어지고, 렘수면기간이 짧아지고 렘수면 잠복기(REM laten$\mathrm{cy}$ )가 길어지는 첫날밤효과(first night effect)가 나타날 수 있다. ${ }^{6}$ 렘수면행동장애를 포착하기 위해서는 렘수면의 양이 중요한 인자로 작용할 것이다. 증례 1에서도 첫 번째 수면다 원검사에서는 렘수면단계(12분, $4 \%$ )가 감소되어 있었으나, 지속기도양압 적정검사에서는 렘수면단계가 39 분(11\%)으로 증가된 것을 알 수 있다. 이 환자에게서 렘수면단계가 증가한 요인으로는 첫날밤 효과가 작용하였을 가능성이 있다. 하지 만 최근 일부 연구에서는 수면다원검사를 연속으로 시행해보 았을 때 렘수면단계가 유의한 차이를 보이고 있지 않아 이전 알려졌던 내용과는 상반된 내용의 결과가 발표된 바 있다. 첫날밤 효과보다 더 중요하게 작용하였을 요인으로는 폐쇄 수면무호흡증 환자에게서 수면다원검사 때 무호흡과 연관 된 각성이 빈번하게 일어나면서 수면의 분절이 오게 되고, 그 결과 렘수면의 양이 감소되었을 것을 생각해 볼 수 있다. 따 라서 지속기도양압 적정검사 때 기도의 양압 유지로 수면무 호흡이 없어지면서 수면의 분절이 줄어 들고 렘수면의 양의 증가되었을 가능성이 있다. 실제로 지속기도양압 치료를 하 면 반동효과로 인해 렘수면이 $20 \%$ 정도 증가된다고 보고된 바 있다. ${ }^{9}$ 즉 지속기도양압 환기를 통해서 수면의 분절이 줄 면서 렘수면이 증가하고 이에 따라 렘수면행동장애가 포착 될 확률이 높아졌을 가능성이 있겠다.

한편 증례 2에서는 첫 번째 수면다원검사에서는 렘수면단 계(50분, $14.9 \%)$ 가 감소되어 있었으며 지속기도양압 적정검 사에서도 렘수면단계(57분, $18 \%)$ 의 기간 자체는 뚜렷한 차 이를 보이지 못하였다. 따라서 총 렘수면기간은 적절히 유지 가 된다 하더라도 무호흡과 연관된 각성으로 인한 잦은 수 면의 분절로 렘수면이 분절되고 각각의 렘수면의 기간이 짧 아지면서 렘수면행동장애가 나타나기 전에 렘수면이 끝나 렘수면행동장애가 충분히 발현되지 못하였을 가능성도 고 려해 볼 수 있겠다.

렘수면행동장애와 수면무호흡증은 병태생리도 다르며 특 히 렘수면행동장애를 치료하기 위해 사용하는 클로나제팜은 수면무호흡증을 악화시킬 수 있다는 점에서 둘을 감별진단 하는 것은 중요하다. Miyamoto 등의 연구에서는 심장에서
의 123I-MIBG 섭취 정도를 비교하였고 이를 가성렘수면행 동장애와 실제 렘수면행동장애를 구분할 수 있는 수단으로 제시하였다. ${ }^{10}$ 둘을 구분하는 여러 가지 진단적인 수단이 연 구되어야겠지만, 지속기도양압요법 동안 수면과 연관된 각 성이 줄어들어 가성렘수면행동장애가 의미 있게 줄어들고 또 한 렘수면이 길어져 렘수면행동장애가 포착될 가능성이 높 아진다는 점을 고려할 때 지속기도양압요법 또한 둘을 구분 하는 한 가지 방법이 될 수 있겠다.

결론적으로, 병력상 렘수면행동장애로 추정되는, 수면 중 이상 행동을 보이는 환자에게서 수면다원검사 때 렘수면행 동장애를 시사하는 소견 없이 폐쇄성수면무호흡만 관찰된다 면, 이 환자가 폐쇄성수면무호흡증으로 인한 가성렘수면행 동장애일 수도 있으나, 수면무호흡증과 실제로 동반된 렘수 면행동장애가 수면무호흡으로 인한 잦은 수면 분절로 인해 가려질 수도 있다는 것을 염두에 둘 필요가 있다. 따라서 폐 쇄성수면무호흡 치료를 위한 지속기도양압 적정검사를 시 행할 때 렘수면행동장애가 진단될 수 있음을 알고 주의를 기울일 필요가 있겠다.

\section{REFERENCES}

1. Duchna HW. [Sleep-related breathing disorders--a second edition of the International Classification of Sleep Disorders (ICSD-2) of the American Academy of Sleep Medicine (AASM)]. Pneumologie 2006; 60:568-575.

2. Iranzo A, Santamaría J. Severe obstructive sleep apnea/hypopnea mimicking REM sleep behavior disorder. Sleep 2005;28:203-206.

3. Brunton LL, Chabner BA, Knollmann BC. Goodman \& Gilman's The Pharmacological Basis of Therapeutics. New York: McGrawHill, 2011; 314.

4. Nalamalapu U, Goldberg R, DiPhillipo M, Fry JM. Behaviors simulating REM behavior disorder in patients with severe obstructive sleep apnea. Sleep Res 1996;25:311.

5. Zhang J, Lam SP, Ho CK, et al. Diagnosis of REM sleep behavior disorder by video-polysomnographic study: is one night enough? Sleep 2008; 31:1179-1185.

6. Suetsugi M, Mizuki Y, Yamamoto K, Uchida S, Watanabe Y. The effect of placebo administration on the first-night effect in healthy young volunteers. Prog Neuropsychopharmacol Biol Psychiatry 2007;31:839-847.

7. Schenck CH. Clinical and research implications of a validated polysomnographic scoring method for REM sleep behavior disorder. Sleep 2005;28:917-919.

8. Cygan F, Oudiette D, Leclair-Visonneau L, Leu-Semenescu S, Arnulf I. Night-to-night variability of muscle tone, movements, and vocalizations in patients with REM sleep behavior disorder. J Clin Sleep Med 2010;6:551-555.

9. Brillante R, Cossa G, Liu PY, Laks L. Rapid eye movement and slowwave sleep rebound after one night of continuous positive airway pressure for obstructive sleep apnoea. Respirology 2012;17:547-553.

10. Miyamoto T, Miyamoto M, Suzuki K, et al. Comparison of severity of obstructive sleep apnea and degree of accumulation of cardiac 123IMIBG radioactivity as a diagnostic marker for idiopathic REM sleep behavior disorder. Sleep Med 2009;10:577-580. 